\title{
Baseline Model for Electricity Generation Expansion Planning for The Philippines: A Leap Model Application
}

\author{
Bryan Joseph C. Nobleza ${ }^{\mathrm{a}, \mathrm{b}, *}$, Emmanuel R. Arriola ${ }^{\mathrm{a}, \mathrm{c}}$, Michael Angelo A. Pedrasa ${ }^{\mathrm{a}, \mathrm{d}}$ \\ ${ }^{a}$ Energy Engineering Program, National Graduate School of Engineering, University of the Philippines Diliman, Quezon City, Philippines \\ ${ }^{b}$ Electrical Engineering Department, College of Engineering and Agro-Industrial Technology, University of the Philippines Los Baños, \\ College, Batong Malake, Los Baños, Laguna, 4031, Philippines \\ ${ }^{c}$ Mechanical Engineering Department, De La Salle University, 2401 Taft Avenue, Manila, 0922, Philippines \\ ${ }^{d}$ Electrical and Electronics Engineering Institute, University of the Philippines Diliman, Quezon City, 1900, Philippines \\ Corresponding author: "bcnobleza@up.edu.ph
}

\begin{abstract}
Philippines is one of the fastest-growing economies and most populated countries globally, greatly affecting its energy demand. The increase in demand leads to an increase in the electricity generation sector's capacity to maintain the supply-demand balance. Thus, this may lead to power shortage, high generation costs, and increased greenhouse gas emissions without proper energy planning. This study aims to create a Long-Range Energy Alternatives Planning System (LEAP)-based Baseline Model for the Philippines' generation expansion planning. The model will serve as a tool for the government and energy planners to develop a longterm generation expansion planning model. The model simulates the technological, economic and environmental aspect of the existing Philippine power generation system that can be used as a baseline for developing a Business-As-Usual Scenario and Alternative Scenario models to assess different energy policy pathways. The developed LEAP model following an independent multi-regional and national scale structure that is based on the Philippine grid and off-grid based regions showed an accurate result with the actual data. The model was able to replicate the actual power generation through the set-up of basic parameters. Development of Philippine LEAP structure; and the establishment of the demand, transformation, and resources module's structure are based on the set of data input parameters. The baseline model developed can be used for continuing studies such as impact evaluation of energy policy for long term power generation expansion planning.
\end{abstract}

Keywords - LEAP; energy modelling; Philippine energy planning; policy.

Manuscript received 26 Jul. 2020; revised 27 Jan. 2021; accepted 11 Feb. 2021. Date of publication 30 Apr. 2021. IJASEIT is licensed under a Creative Commons Attribution-Share Alike 4.0 International License.

\section{INTRODUCTION}

The Philippines is challenged in meeting the future total final energy demand of 57.22 MTOE and electricity demand of 13.30 MTOE in 2030 [1], especially since the country has a very narrow reserve margin of $7.98 \%$ in 2015 . To meet the future demand and maintain a $25 \%$ reserve margin, a total additional generation capacity of $43,765 \mathrm{MW}$ is necessary by the year 2040, and this is equivalent to a capacity addition of $233.23 \%$ increase from the year 2015 [2]. The expected fossil fuel reliance on electricity generation by 2030 is approximately $60 \%$, while the country is committed to implementing a GHG reduction by $70 \%$ in 2030 through the COP 21 agreement [1], [3]. Moreover, the Philippines has the highest electricity rate in all industrial, commercial, and domestic categories than other ASEAN nations and even compared to wealthy countries like Singapore [4].
The energy sector's characteristics for developing countries are the reliance on traditional energies, presence of large informal sectors, urban-rural divide, poverty, the structural transition from traditional to modern lifestyles, blackouts and low performance of energy utilities, social and economic barriers to capital flow and slow technology dispersion/expansion [5]-[7]. The top-down approach of demand analysis is less suitable in developing countries due to the large informal sector's economic activities, reliance on non-marketed fuels, and low-efficiency technologies [6]. The bottom-up or accounting-type models have flexible data inputs and focus on scenarios that make it appropriate for developing countries. The LEAP energy modeling is a bottom-up or accounting-type tool suitable for a developing country that can take rural-urban divide, economic transition, informal sector, and energy shortage features into account [8]. 
The development of a LEAP-based Baseline model for generation expansion planning (GEP) for the Philippines serves as a government and energy planner's tool. Further develop models that assess and evaluate different energy policy scenarios in support of long-term energy planning to be able to formulate strategic pathways to ensure sustainable energy security, energy access, promote a low carbon future and determine optimal capacity mix.

The Baseline Model provides simulation of the technological, economic, and environmental aspects of the existing power generation system that can be used as a baseline for developing a Business-As-Usual Scenario and Alternative Scenario models to assess energy policy pathways. The model results would provide essential information on both national and regional electricity consumption, electricity generation, generation mix, generation capacity, capacity mix, cost of production, greenhouse gas (GHG) emission that the policymakers needed to make sound decisions.

\section{MATERIALS AND METHOD}

The LEAP-based baseline model for GEP for the Philippines was developed using the modeling tool software LEAP system version 2018.0.1.24. The base year was set to 2015 due to the availability and completeness of data as discussed in the literature review and data gathering section of this research. Since 2015 is the base year used in PDP 20162040 , this provides an opportunity to validate the baseline model results. The Philippine LEAP structure is based on the Philippine grid and off-grid power transmission network structure, represented by multi-region: Luzon, Visayas, Mindanao, Palawan, and Mindoro. The demand disaggregation per sector aligned with the DOE Power Statistics report, such as Residential, Commercial, Industrial, and Others. And the Electricity Generation branch accounts for all the power plants per region disaggregated per generation technologies.

\section{A. Data Gathering}

The energy model usage were obtained from the actual reports of the Department of Energy [1], [2], [4], [9]-[12], UPNEC \& ADB [13], US EIA [3], and IEA [3], [14], [15].

\section{B. Demand Module}

The base year's electricity demand was inputted in the technology's final energy intensity variable with the energy intensity branch. It is under the demand sector branches of the demand module at the Current Accounts Scenario in the Analysis View.

TABLE I

2015 ELECTRICITY CONSUMPTION PER SECTOR

\begin{tabular}{lllll}
\hline $\begin{array}{l}\text { Region/ } \\
\text { Sector }\end{array}$ & $\begin{array}{l}\text { Residential } \\
(\mathbf{G W h})\end{array}$ & $\begin{array}{l}\text { Commercial } \\
\text { (GWh) }\end{array}$ & $\begin{array}{l}\text { Industrial } \\
(\mathbf{G W h})\end{array}$ & $\begin{array}{l}\text { Others } \\
\text { (GWh) }\end{array}$ \\
\hline Luzon & $16,286.15$ & $17,135.34$ & $15,824.53$ & 861.04 \\
Palawan & 91.94 & 78.37 & 11.78 & 25.89 \\
Mindoro & 149.65 & 58.76 & 39.56 & 26.30 \\
Visayas & $3,068.12$ & $1,418.32$ & $3,268.07$ & $1,010.74$ \\
Mindanao & $3,151.18$ & $1,393.99$ & $3,369.94$ & 538.07 \\
\hline
\end{tabular}

This data represents the energy (electricity) requirements of each sector across all regions. Table 1 summarizes the base year electricity demand per region in GWh.

\section{Transformation Module}

The system loss in this study is defined as the sum of the Own-use Loss and T\&D losses. This accounts for the energy losses acquired from the energy consumption of power plants due to their operation and the energy losses upon the delivery of electricity to consumers through the power transmission and distribution network.

The system load shape is from the base 2015 actual 8760hours load data of each grid or region. The generation technologies are existing in each region. It is derived from the list of all existing power plants disaggregated per generation technology in the base year. Such disaggregation is considered to represent better and accounts for the actual conversion technologies available in the country that is supplying electricity.

Each generation of technology is characterized by the techno-economic properties referred hereto as power plant technology and economic parameters. The power plant economic parameters include the overnight capital cost, fixed operation and maintenance (O\&M) cost, and variable (O\&M) cost. The power plant dispatch order was as followed: baseload, mid-merit, and peaking plants. The model followed the "Must" dispatch of RE technologies and "Priority" dispatch of biomass technology and has been integrated into the merit order schedule.

The planning reserve margin entered in the model is $25 \%$ across all Luzon, Visayas, Mindanao, Palawan, and Mindoro regions. For off-grid, Palawan, and Mindoro, DOE is still in the process of determining the best value for reserve margin; however, for the matter of uniformity in the model, $25 \%$ also has been used. The GHG emission factor used in the model was based on the LEAP Technology and Environmental Database (TED) that utilizes data from the Intergovernmental Panel on Climate Change (IPCC).

\section{Resource Module}

The Resources Module are the primary and secondary resources, and these are the fuels used by the generation technologies in the Transformation module. These are automatically produced by LEAP depending on the generation technology used in the Electricity Generation branch. Since RE technologies consume renewable natural resources, their fuel cost is considered free, while fossil fuels' base year costs are based on literature.

\section{RESULTS AND DISCUSSION}

\section{A. Baseline Model Evaluation}

The baseline model aimed to capture the actual generation in the base year given the set of data input parameters, settings, and structure. To evaluate the baseline model's accuracy, the generation per technology per region: Luzon (Integrated), Visayas, and Mindanao, was simulated and compared with the actual generation data [1]. A series of the simulation were iterated to get the actual availability of the different generation technologies per region in the base year. 
TABLE II

2015 POWER PLANT AVAILABILITY

\begin{tabular}{lllllll}
\hline Technology & $\begin{array}{l}\text { Base Reference } \\
(\%)\end{array}$ & $\begin{array}{l}\text { Visayas } \\
(\%)\end{array}$ & $\begin{array}{l}\text { Mindanao } \\
(\%)\end{array}$ & $\begin{array}{l}\text { Luzon } \\
(\%)\end{array}$ & $\begin{array}{l}\text { Palawan } \\
(\%)\end{array}$ & $\begin{array}{l}\text { Mindoro } \\
(\%)\end{array}$ \\
\hline Coal & 85.000 & 75.410 & 60.895 & 82.874 & - & - \\
Diesel & 85.000 & 85.000 & 86.530 & 85.000 & 85.000 & 85.000 \\
Bunker & 85.000 & 85.000 & 86.530 & 85.000 & 85.000 & 85.000 \\
Oil & 85.000 & 85.000 & - & 85.000 & - & - \\
Natural Gas & 90.000 & 10.770 & - & 86.938 & - & - \\
Geothermal & 90.000 & 73.900 & 88.560 & 65.242 & - & - \\
Hydro & 55.000 & 35.000 & 40.760 & 25.074 & - & 25.074 \\
Wind & 20.000 & 18.260 & - & 20.415 & - & - \\
Biomass & 60.000 & 16.450 & 3.360 & 29.190 & - & - \\
Solar & 15.000 & 9.900 & 1.440 & 10.992 & - & - \\
\hline
\end{tabular}

Table 2 shows the corresponding power plant availability to produce results capturing the actual 2015 generation per technology. It can be seen from the table that the availability values derived through LEAP differ significantly from the base reference. Most of the generation technologies have a lower actual availability value compared to the base reference. Large differences were found, especially among the RE technologies, and variations were aligned with the location (region). Applying this data to the baseline model, Fig. 1 shows the LEAP generation per technology results compared with actual 2015 DOE data.

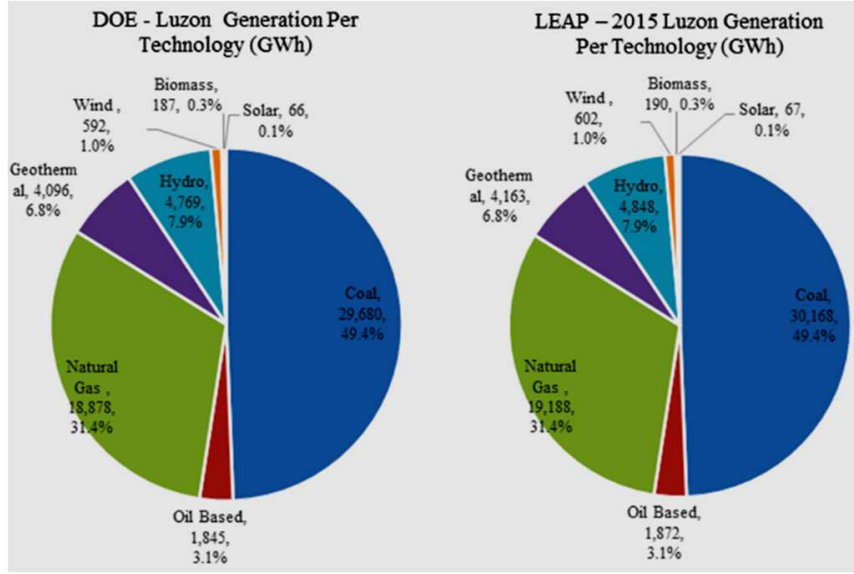

Fig. 1 Luzon Generation Per Technology DOE Report vs LEAP GEP-OPM

\section{B. Philippine Electricity Generation}

Simulation shows that the Philippine total electricity generation in the base year was 82.413 Thousand GWh that is in concurrence with the DOE report. Luzon had the highest share of $73.47 \%$ at 60.551 Thousand GWh, as shown in Fig. 2. This is followed by Visayas and Mindanao, with shares of $13.57 \%$ and $12.29 \%$ at 11.184 Thousand GWh and 10.130 Thousand GWh, respectively. Lastly, Palawan and Mindoro regions had the lowest share of $0.29 \%$ and $0.38 \%$ at 0.235 Thousand GWh and 0.314 Thousand GWh, respectively.

The Philippine electricity generation requirement is mainly sourced from coal technology, having a share of $44.6 \%$ at 36,771.665 GWh, as shown in Fig. 3. It is followed by RE technologies at $25.0 \%$, with geothermal and hydro as the main contributor. Geothermal produced 10,615.026 GWh while hydro, on the other hand, produced 8,740.286 GWh comprising $12.9 \%$ and $10.6 \%$ of the total generation. Wind, biomass and solar shares were $0.9 \%, 0.4 \%$ and $0.2 \%$ respectively. Natural gas share was $23.3 \%$ and produced
19,188.464 GWh of electricity, while oil-based technologies shares were at $7.1 \%$ at $5,858.314 \mathrm{GWh}$.

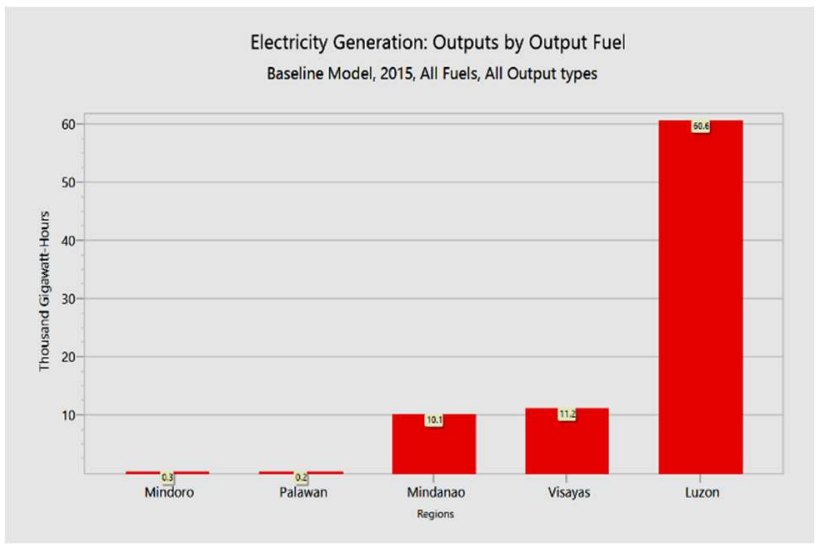

Fig. 2 Philippine Electricity Generation - Baseline Model

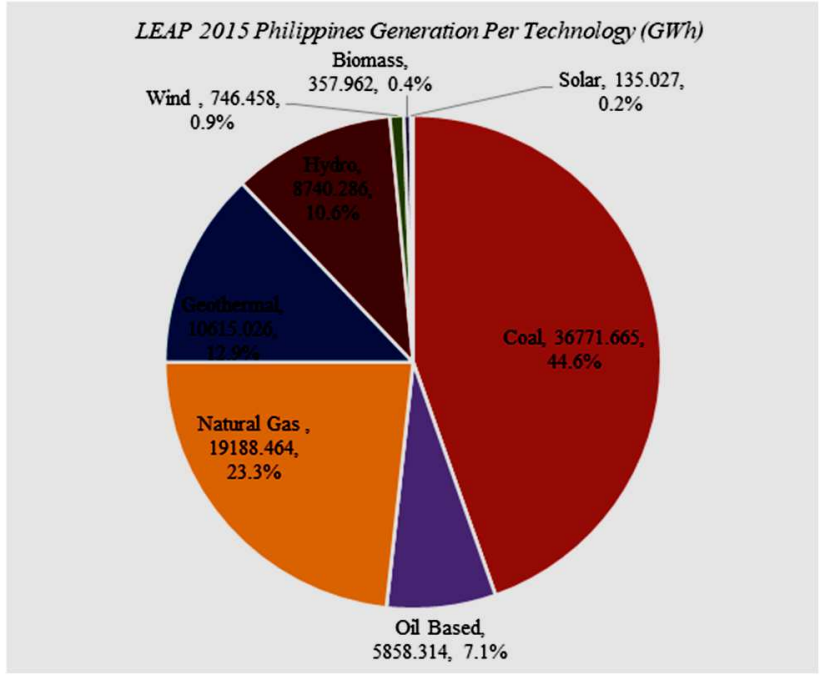

Fig. 3 Philippine Generation Mix - Baseline Model

\section{Philippine Capacities}

Coal had the largest share in the Philippine capacity mix in the base year with a capacity of 5,959 MW comprising $31 \%$ of the total capacity, as shown in Figure 4. It is followed by oil-based and natural gas technologies at $20.7 \%$ and $15.2 \%$, with capacities of 3,989.67 MW and 2,915.90 MW, respectively. The main contributors in RE were geothermal and hydro. Geothermal had a capacity of 1,915.90 MW while hydro, on the other hand, had a capacity of 3,617.45 MW comprising $10 \%$ and $18.8 \%$ of the total installed capacity. 
Wind, biomass and solar shares were $2.2 \%, 1.3 \%$ and $0.9 \%$, respectively.

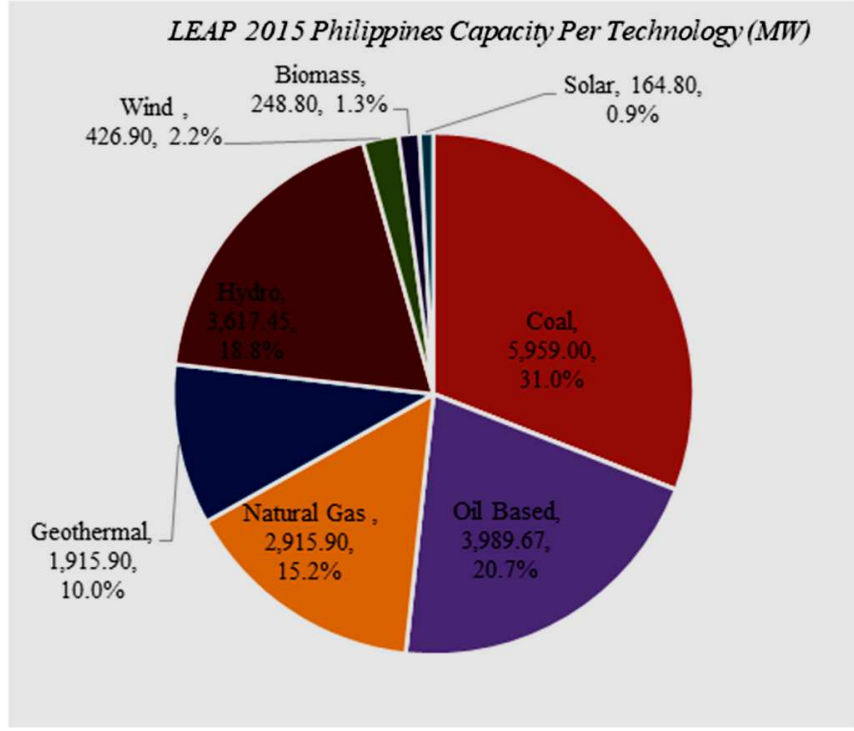

Fig. 4 Philippine Capacity Mix - Baseline Model

\section{Philippine GHG Emission}

The Philippines 2015 GHG emission in electricity generation was 46.89 Million Metric Tonnes of CO2e (MMTCO2e) based on Philippines Key Energy Statistics [12]. Based on the simulation, the Philippines power generation sector had a total GHG emission of 48.7 MMTCO2e, from which $80.49 \%$ came from the Luzon region with an amount of 39.2 MMTCO2e. It is then followed by Visayas and Mindanao, which are far lower than Luzon, with emissions of 4.8 MMTCO2e and 4.3 MMTCO2e, respectively, which are $9.89 \%$ and $8.80 \%$ of the total. Lastly, Palawan and Mindoro emission of both 0.2 MMTCO2e and shared $0.35 \%$ and $0.46 \%$ of the total.

The LEAP-based baseline model was developed to replicate the Philippines' actual power generation system through basic parameters and region modules. This set-up forms the Philippine LEAP structure and establishes the demand, transformation, and resources modules structure through the collected set of data input parameters and the corresponding appropriate assumptions upon data unavailability. Such input data were derived from a series of data gathering from publicly available literature and published reports and expert consultations from DOE. Results or output information were presented through electricity consumption, electricity generation, production cost, system LCOE, and GHG emission. The established model serves as the basis for developing the Business-As-Usual Scenario model as well as the Alternative Scenario models to be used in strategic long-term energy planning for generation expansion.

\section{A. Baseline Model Evaluation}

The baseline model replicated the Philippines' actual power generation system given the set of data input parameters, settings, structure, and the corresponding appropriate assumptions. It produced results in terms of electricity generation per technology and GHG emissions that were similar or equal to the actual data in the base year. Therefore, this implies that the model is sound and accurate; and can be used to develop further scenario models for generation expansion.

The baseline model was evaluated through an iterative simulation of generation and checking for the generation per technology per region to determine if values match the actual base year data by adjusting the maximum available per technology. The derived maximum availability values from the model have a significant difference from the base reference. Also, most of the generation technologies have a lower maximum availability value compared to the base reference. This may imply that power plants' actual electricity production was lower than expected relative to the base reference that is considered an international standard based on existing literature.

Actual electricity production can be associated with power plants' performance in terms of generation if it is delivering the expected amount of electricity to meet the demand based on its actual maximum availability. Since the actually derived availability is lower, it may imply that the corresponding type of power plants are not generating at the same rate as the standard. A large difference was found, especially to the RE technologies and it varies depending on the location (region). This phenomenon may indicate that the yield of RE is low such that the electricity production was greatly affected, or power plant shutdown or intermittency are too frequent.

\section{B. Philippine Electricity Generation}

The simulation shows that the Philippine total electricity generation was 82.413 Thousand GWh, and it is in concurrence with the base year's actual data [4]. This further supports the accuracy and soundness of the developed model. Based on the results, Luzon had the highest share of $73.47 \%$. This is far larger than other regions implying that the electricity consumption, which can be assumed that drives the country's economic activity, is concentrated in Luzon. This is followed by Visayas and Mindanao, with shares of $13.57 \%$ and $12.29 \%$, respectively. It can be observed that the generation from the two regions was at the same level indicating similar economic activity in the context of electricity generation. Lastly, Palawan and Mindoro regions had the lowest share of $0.29 \%$ and $0.38 \%$, respectively, since both had a very low electricity consumption. Such low electricity consumption can be accounted for due to its smaller population and land area and less electricity-driven economy than Luzon, Visayas and Mindanao.

It can be observed from further results that $83.7 \%$ of the total generation in the Luzon is sourced from fossil fuel technology, especially coal and only $16.3 \%$ from RE. Visayas and Mindanao had a considerable balance between fossil fuel and RE technologies, while Palawan and Mindoro were dependent on fossil fuel technology. Furthermore, $75 \%$ of the Philippines' total generation was sourced from fossil-fuel technology, and only $25 \%$ were from RE. Such dependence on fossil fuel technology shall promote GHG emission and may contradict an energy pathway towards the country's compliance to the COP 21 agreement.

\section{Philippine Capacities}

The simulation result that the Philippine total power plant capacity was 19,238.42 Megawatts (MW), and it is in 
concurrence with the base year's actual data [11]. Luzon had the highest share of $72.03 \%$. This is far larger than other regions implying that the electricity consumption and power generation development is concentrated in Luzon. This is followed by Visayas and Mindanao, with shares of $14.13 \%$ and $12.84 \%$. It can be observed that the capacities from the two regions were at the same level, indicating that the electricity consumption that drives the capacity expansion is similar. Lastly, Palawan and Mindoro regions had the lowest share of $0.51 \%$ and $0.47 \%$, respectively. The generation capacity is driven by electricity demand or consumption. Such a low share in generation capacity can be accounted for due to low electricity consumption compared to Luzon, Visayas, and Mindanao.

It can be observed from further results that $72.3 \%$ of Luzon's total installed capacity was sourced from fossil-fuel technology, and only $27.7 \%$ were from RE. Visayas and Mindanao power capacities had a considerable balance between fossil fuel and RE technologies, while Palawan and Mindoro were fossil fuel technology dependent. Furthermore, it can be observed that $66.9 \%$ of the total installed capacity of the Philippines was sourced from fossil-fuel technology, and only $33.1 \%$ were from RE. This implies that the Philippine power capacity that supports the economy was dominated by fossil fuel technologies, especially coal.

\section{Philippine Cost of Production}

The simulation result shows that the Philippines had a total production cost (electricity) of Million USD 4,322. Luzon had the highest production cost, which comprises the $78.07 \%$ of the total cost of generation of the Philippines. This indicates that the electricity consumption and the country's corresponding economic activity are concentrated mainly in Luzon. Visayas and Mindanao follow it with $9.92 \%$ and $10.73 \%$ of the total production cost, respectively. It can be implied based on these results that Visayas and Mindanao, though a major island/region, were far behind the electricity consumption of Luzon, indicating that the electricity consumption and the related economic activity was far behind compared to Luzon. Lastly, Palawan and Mindoro production costs were $0.56 \%$ and $0.72 \%$ of the total cost of production of the Philippines.

The system Levelized cost of electricity (LCOE) is defined in this model as the ratio of the total cost of production and the total electricity generation from all the generation technologies present in the system. Palawan and Mindoro, even though having the lowest cost of production, had the highest cost of electricity. This is due to the dependency on oil-based generation technology that has a high fuel cost due to imported oil.

\section{E. Philippine GHG Emission}

The Philippines' GHG emission in 2015 from electricity generation was 46.89 Million Metric Tonnes of $\mathrm{CO} 2 \mathrm{e}$ (MMTCO2e) [12]. Based on the simulation result, the Philippines power generation sector produced almost similar total GHG emission of 48.7 MMTCO2e. This further supports the developed model's accuracy and soundness since the actual is at par with the simulation result.

Luzon had the highest share of $80.49 \%$. This implies that the far largest contributor to $\mathrm{CO} 2$ emission in the country is
Luzon in the context of power generation. This came about since Luzon had the far highest electricity consumption, generation and capacity; and is dominated by fossil fuel technology, especially coal. It is then followed by Visayas and Mindanao, which are far lower than Luzon, which is $9.89 \%$ and $8.80 \%$ of the total, respectively. Lastly, Palawan and Mindoro had an emission of both 0.2 MMTCO2e and shared the $0.35 \%$ and $0.46 \%$ of the total.

The result extracted from the baseline model has shown similar values from the Philippines' actual power generation system. It can be concluded that the baseline model is sound and accurate since the electricity generation, capacity, and GHG emission results conform to the actual data based on DOE reports. It can also produce information on cost of production and LCOE. Moreover, it can be concluded based on the results that Luzon had the far highest electricity generation, capacity, cost of production and GHG emission, implying that the economic activity and power generation development are concentrated in this region. Furthermore, the Philippines is relying mainly on fossil fuel technologies in power generation to support its economy.

The Philippine LEAP structure is based on the Philippine grid and off-grid power transmission network structure, represented by multi-region: Luzon, Visayas, Mindanao, Palawan and Mindoro. This modelling structure can benefit in terms of accuracy by considering the grid and off-grid scenario. This structure shall provide future regional studies with a flexible baseline to be used to develop alternative scenarios.

The Philippine total primary supply data and projection are not included in the study. Thus, the yield of renewable energy resources was set to unlimited, and the availability of fossil fuels, on the other hand, was set to unlimited as well since they can be imported. The study focuses on the transformation or generation expansion. It assumes that the needed resources are always present in the system or can be provided, whether from indigenous or imported resources. While the resources are assumed unlimited, the generation technologies' output is being limited or constrained by its maximum availability property in the Transformation module.

Future study is the use of the model to assess the impacts of optimal pathways pertaining to COP 21 scenario, zero coal scenario, EV scenario, aggressive nuclear scenario and aggressive RE scenario. Assessment of high RE technology penetration on the grid should be considered as well for future study. Also, the integration of the Philippine total primary energy supply model is recommended to capture the actual Philippine primary resources market conditions and provide a holistic approach to energy sector analysis.

\section{CONCLUSION}

The Baseline LEAP-based model for generation expansion planning for the Philippines was developed through the LEAP framework. Simulations were conducted using the model to assess the technological, economic, and environmental impacts (GHG emission) of the base year 2015. The model's data input and assumptions were based on publicly available and published reports and information such as DOE published reports, published journals and reports from international energy agency and organization, DOE consultations, and data availability limitation. The baseline model developed was 
based on the 2015 Philippine power generation system disaggregated through the grid and off-grid based regions: Luzon, Visayas, Mindanao, Palawan and Mindoro, thus, creating an independent multi-regional and a national scale structure in the model.

The model was able to replicate the Philippines' actual power generation system through the set-up of appropriate basic parameters. Development of Philippine LEAP structure; and the establishment of the demand, transformation and resources module's structure that is based on the collected set of data input parameters and the corresponding appropriate assumptions upon the unavailability of data. It can be concluded that the developed baseline model is sound and accurate since the electricity generation, capacity and GHG emission results conform to the actual data. The developed Baseline model can be used reliably for impact evaluation of energy policy for long term power generation expansion planning.

\section{ACKNOWLEDGMENT}

The authors are grateful to DOST-ERDT and DOSTPCAARRD for providing financial support to accomplish this research. Also, the authors thank Prof. Rowaldo Del Mundo and Engr. Roger Buendia of the University of the Philippines Diliman for the valuable support and guidance. Lastly, the authors extend appreciation towards the DOE team (EPIMB, EPPB, and REMB-NREB) for the utmost cooperation during the study's duration.

\section{REFERENCES}

[1] Department of Energy, "Philippine Energy Plan 2016-2030," 2015.

[2] Department of Energy, "Power Development Plan 2016-2040 Powering the Nation," 2016.

[3] E. I. Aministration, "Capital Cost Estimates for Utility Scale Electricity Generating Plants. US Department of Energy, Energy Information Administration," 2013. [Online]. Available: https://www.eia.gov/analysis/studies/powerplants/capitalcost/pdf/cap cost assumption.pdf

[4] Department of Energy, "2015 Philippine Power Statistics," 2016.

[5] F. Urban, R. M. J. Benders, and H. C. Moll, "Modelling energy systems for developing countries," Energy Policy, vol. 35, no. 6, pp 3473-3482, 2007/06/01/ 2007, doi: https://doi.org/10.1016/j.enpol.2006.12.025.

[6] S. C. Bhattacharyya, "Applied general equilibrium models for energy studies: a survey," Energy Econ., vol. 18, no. 3, pp. 145-164, 1996/07/01/ 1996, doi: https://doi.org/10.1016/0140-9883(96)000138.

[7] R. Pandey, "Energy policy modelling: agenda for developing countries," Energy Policy, vol. 30, no. 2, pp. 97-106, 2002/01/01/2002, doi: https://doi.org/10.1016/S0301-4215(01)00062-3.

[8] A. J. Seebregts, Goldstein, G. A., \& Smekens, K. "Energy/Environmental Modeling with the MARKAL Family of Models BT," Operations Research Proceedings 2001, 2002.

[9] Department of Energy, "Energy Demand \& Supply Outlook 2017 2040," 2018. [Online]. Available: https://www.napocor.gov.ph/images/doe/PEP 20172040_Energy_Demand_\&_Supply_Outlook.p̄pd.

[10] Department of Energy, "Philippines Key Energy Statistics Retrieved," 2014.

[11] Department of Energy, "Philippine Power Statistics, Summary of Installed Capacity, Dependable Capacity, Power Generation and Consumption (2003-2016). , 2017. [Online]. Available: https://www.doe.gov.ph/sites/default/files/pdf/energy statistics/sum mary 2016 power statistics final march 27 2017.pdf.

[12] Department of Energy, "Philippines Key Energy Statistics," 2017. [Online]. Available: https://www.doe.gov.ph/sites/default/files/pdf/energy_statistics/2017 _key_energy_statistics.pdf

[13] Asian Development Bank, "Low Carbon Development in the Philippines Household, Road Transport and Power Generation Sectors," 2015.

[14] E. I. Administration, "Electric Power Annual 2017 Electric Power Annual 2017 Revision Notice," 2018. [Online]. Available: www.eia.gov

[15] U. S. E. I. Administration. Primary energy consumption [Online] Available: https://www.eia.gov/international/data/world/totalenergy/total-energy-consumption 